\title{
Treatment of hypernatraemic dehydration in infancy
}

\author{
ANN BANISTER, S. A. MATIN-SIDDIQI, and G. W. HATCHER* \\ From the Department of Child Health, Alder Hey Children's Hospital, Liverpool
}

\begin{abstract}
Banister, A., Matin-Siddiqi, S. A., and Hatcher, G. W. (1975). Archives of Disease in Childhood, 50, 179. Treatment of hypernatraemic dehydration in infancy. Thirty-eight infants with severe hyperosmolar dehydration and hypernatraemia were treated, using three regimens of intravenous fluids: A. $\frac{1}{2}$ normal saline, given fast; B. $\frac{1}{2}$ normal saline given slowly; C. $\frac{1}{5}$ normal saline. 28 of the infants were studied in a treatment trial, and it is concluded that $0 \cdot 18 \%$ saline in $4.3 \%$ dextrose, with the early addition of potassium given at a rate of $100 \mathrm{ml} / \mathrm{kg}$ estimated rehydrated weight per 24 hours gives satisfactory rehydration within 48 hours, with little risk of convulsions.
\end{abstract}

The best means of rehydrating hypernatraemic infants remains controversial. Though there is general agreement that reduction of hyperosmolality should be gradual, some achieve this with slow rates of fluid of low sodium content, while others use faster rates of high sodium content. It was therefore decided to study the use of different intravenous fluid regimens in severely affected infants. As the use of normal saline or full strength Darrow's solution has been incriminated in the production of hypernatraemia in infants originally suffering from normonatraemic dehydration (Skinner and Moll, 1956; Weil and Wallace, 1956; Stickler, 1967; Ahmed and Agusto-Odutola, 1970) this study was confined to a comparison of $0 \cdot 18 \%$ saline in dextrose with $0.45 \%$ saline in dextrose.

\section{Patients and method}

Infants suffering from hypernatraemic dehydration (plasma sodium $>150 \mathrm{mEq} / \mathrm{l}$ ) and a measured plasma osmolality $>350 \mathrm{mOsm} / \mathrm{kg}$ were studied. With the exception of one infant with Down's syndrome, infants known to have previous cerebral or renal abnormalities, which might have influenced the course of treatment, were excluded. During 18 months 37 infants with 38 episodes of hypernatraemia of this severity were studied in 2 children's hospitals. All were suffering from primary water depletion, and subsequent urine excretion showed that all had some degree of sodium and potassium depletion. The primary cause of illness was gastroenteritis in 27, respiratory infection in 8 , septicaemia in 2 , and unknown in one. The one infant seen during this time with evidence of sodium

Received 2 September 1974.

*Present address: Royal Alexandra Hospital for Sick Children, Brighton.
TABLE I

Treatment regimens

\begin{tabular}{|c|c|}
\hline & $0.45 \%$ saline in $5 \%$ dextrose at \\
\hline Group $B$ ' $\frac{1}{2} \mathrm{~N}$ fast' & $\begin{array}{l}0.45 \% \text { saline in } 5 \% \text { dextrose at } \\
150 \mathrm{ml} / \mathrm{kg} \text { per } 24 \mathrm{~h}\end{array}$ \\
\hline Group C ' $\frac{1}{5} \mathrm{~N}^{\prime}$ & $\begin{array}{l}0.18 \% \text { saline in } 4.3 \% \text { dextrose at } \\
100 \mathrm{ml} / \mathrm{kg} \text { per } 24 \mathrm{~h} \\
\text { Solutions given intravenously in volumes } \\
\text { calculated on the basis of estimated rehydra- } \\
\text { ted weight for the first } 48 \text { hours of treatment. } \\
\text { If oral intake introduced during this time, } \\
\text { drip rate reduced accordingly, so that total } \\
\text { volume and type of fluid received remains } \\
\text { the same. After } 48 \text { hours fluid and feeds } \\
\text { given as desired }\end{array}$ \\
\hline
\end{tabular}

All infants

(1) If in circulatory failure, intravenous plasma given fast, about $20 \mathrm{ml} / \mathrm{kg}$

(2) If severe clinical acidosis accompanying shock, an immediate dose of $8 \cdot 4 \%$ sodium bicarbonate given, about $3 \mathrm{mEq} / \mathrm{kg}$. Otherwise, severe acidosis (base deficit $>10 \mathrm{mEq} / \mathrm{l}$, or standard bicarbonate $<13 \mathrm{mEq} / \mathrm{l}$ ) half corrected with bicarbonate in drip chamber

(3) Potassium chloride $26 \mathrm{mEq} / 1(1 \mathrm{~g}$ in $500 \mathrm{ml})$ added when urine passed, unless plasma potassium still high

(4) Phenobarbitone $15 \mathrm{mg} \mathrm{12}$-hourly by intramuscular injection as initial sedation

overload was not included, as the management of this condition presents a different problem. The majority of infants were nursed in a special unit, and initial care was provided by ourselves or by the admitting team on duty before transfer to us.

Infants were treated in one of three ways (Table I). The regimens were based on the usual method of treatment of dehydration used in Liverpool. Plasma was 
given rapidly as a plasma expander to any infant admitted with signs of peripheral circulatory failure-cold mottled extremities, tachycardia, and absent peripheral pulses. Sodium bicarbonate was used to partially correct severe acidosis. Infants with hypernatraemia severe enough to have a plasma osmolality $>350$ $\mathrm{mOsm} / \mathrm{kg}$ were assessed as being at least $10 \%$ dehydrated. Where there was peripheral circulatory failure the degree of dehydration was considered to be nearer $15 \%$. The final rehydrated weight used in calculations was taken as the maximum weight reached between 48 and 72 hours of treatment in the oedema free, and as the nearest estimate possible as the first oedema-free weight achieved during treatment in the oedematous. Sedation was given to all infants so that neurological signs would be similarly affected.

Numbers with hypernatraemia of this severity were expected to be small, so that to achieve comparable treatment groups random selection was not used, but the grid shown in Table II was devised with the approval of the medical statistician, where treatment was decided on the basis of age and two arbitrary levels of severity. At first the admitting team could choose the treatment; as spaces filled an infant was allocated to the next empty or unbalanced space.

Infants were weighed on admission and at least once daily thereafter. Plasma osmolality, urea, electrolytes, calcium, and glucose were measured on admission and once or twice daily until normal. The osmolality of each urine sample was measured until diuresis occurred. CSF was examined initially because of neurological signs, and CSF osmolality, urea, and electrolytes were also measured. It was thought justifiable to obtain a second sample about 24 hours later for comparison.

The neurological state was graded on admission or after initial resuscitation in the shocked infant, and frequently during treatment as follows. 0 nothing unusual. 1 irritable, or poorly responsive and irritable when disturbed. 2 increased tone with or without neck stiffness. 3 jittery movements, with or without nystagmoid eye movements. 4 convulsing.

Deterioration during treatment was scored if there was an increase in neurological grade. The absence of convulsions during treatment was considered the most objective and important criterion of success, and the treatment trial was terminated when there was a significant difference in the incidence of convulsions between treatment groups. During the trial frequent convulsions in those infants treated with fast $\frac{1}{2} \mathrm{~N}$ saline made us decide that no further infants admitted with severe neurological signs (grade 3 or 4) should be treated in this way. As this policy worked against the final conclusions we do not feel it invalidated the trial.

Ten infants were removed from the treatment trial (see Table VI). One was treated with a mixture of $\frac{1}{2} \mathrm{~N}$ and $\frac{1}{5} \mathrm{~N}$ saline in error. 2 treated with $\frac{1}{5} \mathrm{~N}$ saline were over 6 months old, and there were no infants of comparable age in the $\frac{1}{2} \mathrm{~N}$ saline groups. They were therefore omitted from the calculations. All 3 did well. 7 others were omitted because the effect of treatment could not be judged. 2 were admitted convulsing and continued to do so during the first day of treatment, 2 others who convulsed died of severe brain damage, and 3 required a change of treatment during the study period because of renal complications. One infant who was admitted convulsing and severely pyrexial (temperature $42^{\circ} \mathrm{C}$ ), had no further convulsions from 4 hours after admission when the fever was controlled, and he was therefore left in the treatment trial.

\section{Results}

Treatment trial. Details of the three treatment groups are shown in Table III. The greater apparent dehydration as estimated from weight gain in group B is probably related to the high incidence of oedema during treatment in this group. Group $B$ had a lower average neurological grade on admission as the result of our selection policy.

The course of treatment is shown in Table IV. The average rate of fluid received in each group was close to that aimed at. The rate of fall of plasma osmolality shown was that between 12 and 24 hours of treatment, and was derived from the curve drawn for each infant from the plot of osmolality against time. This time was chosen as most

TABLE II

Allocation of treatment groups

\begin{tabular}{|c|c|c|c|c|}
\hline & $-1 \mathrm{~m}$ & $-3 m$ & $-6 m$ & $>6 \mathrm{~m}$ \\
\hline \multicolumn{5}{|l|}{ Group $A$ ' $\frac{1}{2} \mathrm{~N}$ slow' } \\
\hline & Osm $>380$ & & & \\
\hline \multicolumn{5}{|l|}{ Group $B$ ' $\frac{1}{2} \mathrm{~N}$ fast' } \\
\hline & Osm $>380$ & & & \\
\hline \multicolumn{5}{|l|}{ 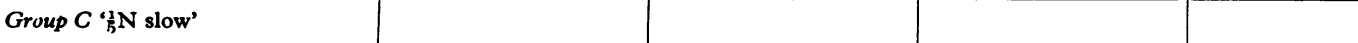 } \\
\hline & Osm $>380$ & & & \\
\hline
\end{tabular}


Treatment of hypernatraemic dehydration in infancy

TABLE III

Comparison of groups (mean $\pm S D$ )

\begin{tabular}{|c|c|c|c|}
\hline & Group $A \frac{1}{2} N$ slow & Group B $\frac{1}{2} \mathrm{~N}$ fast & Group $C_{5}^{1} \mathrm{~N}$ slow \\
\hline No. of cases & 10 & 9 & 9 \\
\hline $\begin{array}{l}\text { Age (w) } \\
\text { Plasma osmolality (mOsm/kg) } \\
\text { Plasma sodium (mEq/1) } \\
\text { Blood urea }(\mathrm{mg} / 100 \mathrm{ml}) \\
\text { Weight loss }(\%) \\
\text { Plasma resuscitation (\% cases) } \\
\text { Neurological grade on admission }\end{array}$ & $\begin{array}{l}7 \cdot 4 \pm 7 \cdot 2 \\
377 \pm 19 \cdot 7 \\
165 \pm 5 \cdot 1 \\
174 \pm 57 \cdot 7 \\
12 \pm 3 \cdot 2 \\
50 \\
1 \cdot 6 \pm 1 \cdot 2\end{array}$ & $\begin{array}{l}7 \cdot 7 \pm 7 \\
387 \pm 25 \cdot 5 \\
169 \pm 7 \cdot 4 \\
189 \pm 60 \cdot 4 \\
13 \pm 2 \cdot 3 \\
56 \\
1 \cdot 3 \pm 0 \cdot 7\end{array}$ & $\begin{array}{l}8 \cdot 4 \pm 5 \\
389 \pm 40 \cdot 8 \\
172 \pm 19 \cdot 8 \\
201 \pm 70 \\
11 \pm 2 \cdot 9 \\
67 \\
1 \cdot 9 \pm 0 \cdot 9\end{array}$ \\
\hline
\end{tabular}

representative of the effect of the intravenous regimen, as before 12 hours plasma osmolality occasionally fell slowly because of uncontrolled fluid losses, and by 24 hours the osmolality was approaching normal in some infants. It will be seen that the groups treated with fast $\frac{1}{2} \mathrm{~N}$ saline and $\frac{1}{5} \mathrm{~N}$ saline had similar rates of fall of plasma osmolality, while the rate was significantly slower in the slow $\frac{1}{2} \mathrm{~N}$ saline group $(P<0.01$ in each case, Student's ' $t$ ' test). In those few infants where two CSF samples were obtained, similar differences in rate of fall of osmolality during the first day of treatment were seen.

Infants treated with fast $\frac{1}{2} \mathrm{~N}$ saline deteriorated more neurologically and there was a high incidence of convulsions in the group compared with the two groups treated slowly (Yates's modification of the $\chi^{2}$ test, $\left.P<0.01\right)$. One infant who convulsed had phenylketonuria, which may have made her more likely to convulse, but excluding her from the calculations the difference is still significant $(P<0 \cdot 05)$. At this stage the trial was ended.

The course of rehydration is shown in Table V. One infant was omitted from the calculations in group $\mathrm{C}$ because she developed renal tubular necrosis, and 2 from group $B$ because their intravenous fluid rate was slowed after convulsions.

Sodium intake was greatest during the first 24 hours of treatment because some infants received plasma and sodium bicarbonate in early therapy. It was of course highest in group B and lowest in group C. Group B also received the most sodium bicarbonate, though differences between the 3 groups were small. The rate of fall of plasma urea during the treatment period 12 to 24 hours was greater for similar falls of plasma osmolality in group B, while plasma sodium fell faster in group C.

The time when a water diuresis occurred (when the urine osmolality fell below that of plasma) was considered to be a measure of the time of effective rehydration, and gave a clearcut end point. On average, infants in groups $B$ and $C$ had diuresis within 43 hours of the start of treatment, while diuresis was much later in group A. The difference between groups $B$ and $C$ was not significant, but they were both significantly different from group A ( $P<0.01$ in each instance). Another measure of rehydration, the time when the plasma osmolality reached $300 \mathrm{mOsm} / \mathrm{kg}$ as read from the plotted curves for each infant, was a less accurate end point,

TABLE IV

Neurological course

\begin{tabular}{|c|c|c|c|}
\hline & $\begin{array}{l}\text { Group A } \\
\frac{1}{2} N \text { slow }\end{array}$ & $\begin{array}{l}\text { Group B } \\
\frac{1}{2} N \text { fast }\end{array}$ & $\begin{array}{l}\text { Group C } \\
\frac{1}{5} \mathrm{~N} \text { slow }\end{array}$ \\
\hline No of cases & 10 & 9 & 9 \\
\hline $\begin{array}{l}\text { Fluid (ml/kg in first } 24 \mathrm{~h} \text { ) } \\
\text { (range) } \\
\text { Rate of fall plasma osmolality (mOsm/h) } \\
\text { Rate of fall CSF osmolality (mOsm/h) } \\
\text { (no. of cases) } \\
\text { Convulsions during treatment } \\
\text { (no. of cases) } \\
\text { Increase in neurological grade during } \\
\text { treatment }\end{array}$ & $\begin{array}{c}\star 104 \pm 10 \cdot 5 \\
(81-116) \\
\star 1 \cdot 1 \pm 0 \cdot 6 \\
\star 0.8 \pm 0.5 \\
(3) \\
0 \\
0.9\end{array}$ & $\begin{array}{c}146 \pm 21 \cdot 2 \\
(121-179) \\
1 \cdot 8 \pm 0 \cdot 8 \\
2 \pm 1 \cdot 2 \\
(4) \\
4 \\
1 \cdot 3\end{array}$ & $\begin{array}{c}96 \pm 12 \cdot 4 \\
(76-107) \\
2 \pm 0 \cdot 8 \\
1 \cdot 7 \pm 0 \cdot 4 \\
(5) \\
0 \\
\quad 0 \cdot 7\end{array}$ \\
\hline
\end{tabular}

$\star$ Mean \pm SD. 
TABLE V

Rehydration data (mean $\pm S D)$

\begin{tabular}{|c|c|c|c|}
\hline & $\begin{array}{l}\text { Group A } \\
\frac{1}{2} \mathrm{~N} \text { slow }\end{array}$ & $\begin{array}{l}\text { Group B } \\
\frac{1}{2} \mathrm{~N} \text { fast }\end{array}$ & $\begin{array}{l}\text { Group C } \\
\frac{1}{5} \mathrm{~N} \text { slow }\end{array}$ \\
\hline No. of cases & 10 & 7 & 8 \\
\hline $\begin{array}{l}\text { Sodium intake (mEq/kg first } 24 \mathrm{~h} \text { ) } \\
\text { Rate of fall plasma osmolality }(\mathrm{mOsm} / \mathrm{h}) \\
\text { Rate of fall blood urea }(\mathrm{mg} / 100 \mathrm{ml} / \mathrm{h}) \\
\text { Oecema during first } 48 \mathrm{~h}(\% \text { cases }) \\
\text { Weight increase at } 24 \mathrm{~h}(\%) \\
\text { Diuresis (h from start of treatment) } \\
\text { Time first urine passed (h) }\end{array}$ & $\begin{aligned} 12 \cdot 7 & \pm 2 \cdot 3 \\
1 \cdot 1 & \pm 0 \cdot 6 \\
2 \cdot 7 & \pm 1 \cdot 1 \\
10 & \\
6 \cdot 3(9) & \pm 1 \cdot 8 \\
61 \cdot 6(8) & \pm 11 \\
6 \cdot 8(9) & \pm 3\end{aligned}$ & $\begin{array}{r}17 \cdot 5 \pm 3 \cdot 2 \\
1 \cdot 9 \pm 0 \cdot 9 \\
3 \cdot 7 \pm 1 \cdot 5 \\
57 \\
9 \cdot 1(6) \pm 5 \cdot 9 \\
32 \cdot 4(5) \pm 7 \cdot 6 \\
5(5) \pm 0 \cdot 5\end{array}$ & $\begin{array}{rl}7 & \pm 3 \cdot 4 \\
2 \cdot 1 & \pm 0 \cdot 7 \\
3 \cdot 2 & \pm 1 \cdot 9 \\
0 & 5 \cdot 7 \pm 2 \\
42 \cdot 8(6) & \pm 7 \cdot 9 \\
4 \cdot 6(8) & \pm 2 \cdot 7\end{array}$ \\
\hline
\end{tabular}

Note: Number tested in parentheses.

but gave similar differences between the groups where it could be assessed. This was on average 63 hours from the start of treatment in group A (7 infants), 50 hours in group B (6 infants), and 49 hours in group $C$ ( 7 infants).

There was a high incidence of clinical oedema in group $B$, which received the most sodium, while no infant in group $\mathrm{C}$ became oedematous. The greater weight gain in group B was thought to be due to the high sodium intake in this group, with overexpansion of the extracellular fluid, rather than an indication of more effective rehydration. Not every infant received potassium as early in treatment as was planned, and more infants in group B were poorly treated in this respect. This was unlikely to have affected the incidence of convulsions, which began between 12 and 26 hours of treatment, as all groups received similar amounts of potassium in the first 24 hours. However, it may well have increased the likelihood of oedema in group B infants, as the potassium intake per $\mathrm{kg}$ body weight in the first 48 hours of treatment was only half as great in the oedematous as in the nonoedematous.

One infant in the treatment trial with Down's syndrome had an uneventful course, and subsequent progress was as expected. One infant treated with fast $\frac{1}{2} \mathrm{~N}$ saline, with an uneventful acute illness, was found to be mentally retarded, failed to thrive, and died 6 weeks later. Further questioning of his very young mother showed that he had always been abnormal. The findings after death suggested that the hypernatraemic illness was not directly responsible for his mental retardation or early death. The other 26 infants were seen at intervals after their acute illness, and between 11 and 19 months later were fully assessed clinically, their developmental quotient (DQ) measured by a psychologist, and an EEG performed. DQ was within normal limits in all 24 infants in whom it was measured, the average being 98 . There were no significant differences between the three treatment groups. EEGs were normal. Only one infant, treated with slow $\frac{1}{2} \mathrm{~N}$ saline, showed signs of neurological damage as the result of his illness. This was the baby admitted convulsing and hyperpyrexial, and he is left with a mild spastic quadriplegia, which makes him clumsy and do poorly in tests of motor attainments. His overall DQ at 20 months of age was 89 .

Infants omitted from the treatment trial. Some details of these infants are shown in Table VI. The first 3 made full recoveries, and on follow-up had normal EEGs and DQs ranging from 97 to 104 . 4 of the 7 very ill infants died as the result of their hypernatraemic illness. The 3 survivors appear to have made full recoveries, with no evidence of neurological damage. Follow-up DQs are 106, 102, and 98 in order of their appearance in Table VI.

\section{Other factors in management.}

Continuing fluid losses. It became apparent during the study that continuing fluid losses from the infant could affect appreciably the rate of rehydration. Continuing diarrhoea was not an important cause in our experience. Tachypnoea, due to respiratory infection or metabolic acidosis, was important (32 of the 38 infants studied had respiratory rates greater than $40 / \mathrm{min}$ on admission), and fluid losses from the lungs could be controlled by nursing the infant in high humidity. Most important, however, was uncontrolled fever (27 infants had temperatures above $38^{\circ} \mathrm{C}$ on admission), which could lead to large loss of water. This dehydration fever was readily controlled by tepid sponging with or without a fan. In the early stages of the study such continuing fluid losses were responsible for poor rates of rehydration and poor falls of plasma osmolality in the first 12 hours of treatment in 2 infants in group A, 2 in 
Treatment of hypernatraemic dehydration in infancy

TABLE VI

Details of infants excluded from treatment trial

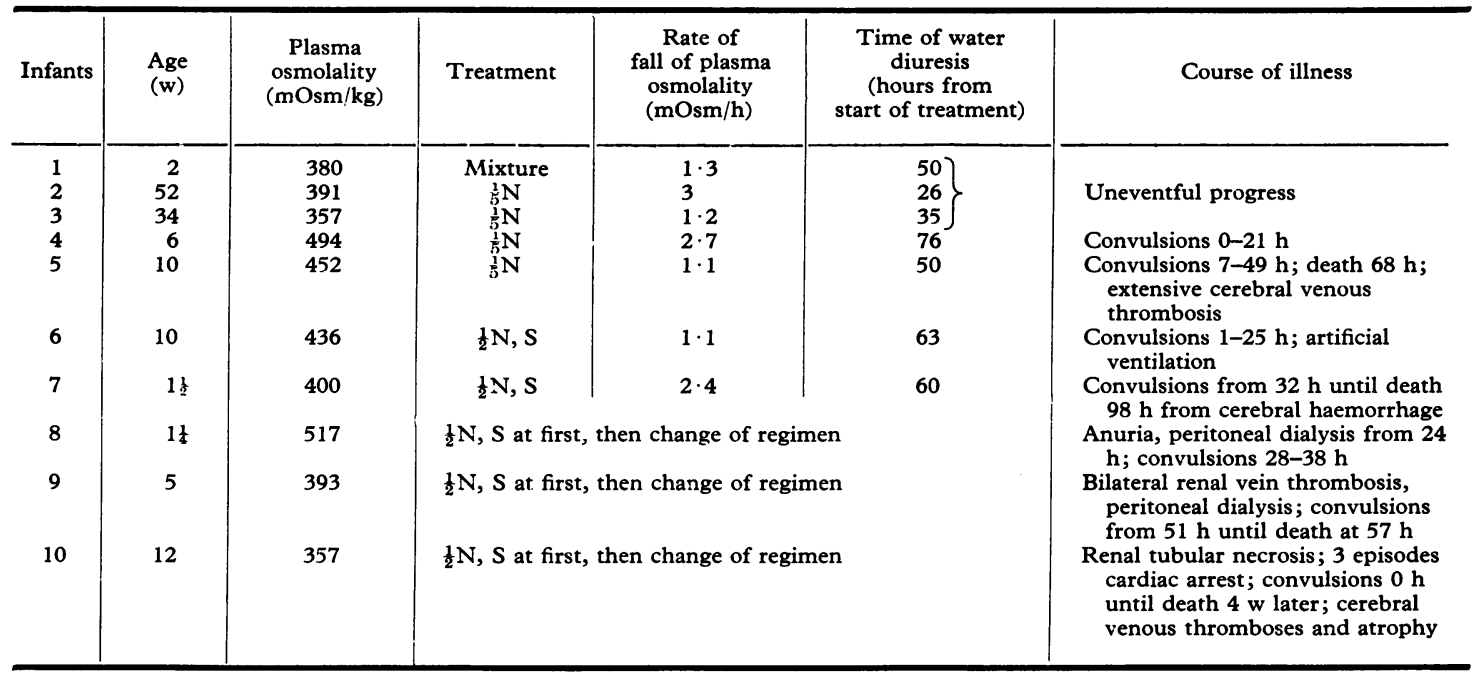

$\mathrm{N}$, normal saline; $\mathrm{S}$, slow.

group B, and one in group C. As these infants were evenly spread between the groups the conclusions about the relative effectiveness of rehydration with the different regimens are not invalid. In 2 of the very ill infants (Table VI) poor rates of hydration may have contributed to the severity of thrombotic lesions: in infant 5 where uncontrolled acidotic breathing was present for the first 16 hours of treatment, and in infant 9 where uncontrolled fever was present for 36 hours. In both initial weight gain and fall of plasma osmolality were unsatisfactory.

Hypocalcaemia. 17 infants with normonatraemic dehydration severe enough to require intravenous therapy were also studied, and they are compared with the severely hyperosmolar infants in the following paragraphs. Plasma calcium tended to fall in both types of dehydration during treatment, but only markedly so in the hypernatraemic. It fell below $8 \mathrm{mg} / 100 \mathrm{ml}$ in 9 hypernatraemic infants and in 2 of 12 normonatraemic infants where it was serially measured. It fell below $7 \mathrm{mg} / 100 \mathrm{ml}$ in 4 hypernatraemic infants. With the exception of one to whom potassium was not given due to administrative error, these were all very ill, and potassium could not be given early in treatment because of persistent hyperkalaemia. Calcium was not used routinely, but was given intravenously to those in whom plasma calcium fell below $7 \mathrm{mg} / 100 \mathrm{ml}$. Its use made no apparent difference to the clinical condition or control of fits.

Hyperglycaemia. The blood glucose was high in many hypernatraemic infants, being $200 \mathrm{mg} / 100$ $\mathrm{ml}$ or more in 9 of 33 infants where it was measured on admission, and $400 \mathrm{mg} / 100 \mathrm{ml}$ or more in $3.25 \%$ had glucose in the first urine passed. Though blood glucose was not measured in the normonatraemic infants, none had glycosuria. In hypernatraemia glycosuria was transient and the raised blood glucose fell rapidly with rehydration alone in all but one infant, who had a further rise after peritoneal dialysis was started, and who responded rapidly to insulin given over 8 hours. Blood glucose then remained normal despite continuing dialysis.

Anaemia. Haemoglobin was often low in hypernatraemic infants, especially after correction of initial haemoconcentration. 11 hypernatraemic infants and one normonatraemic had $\mathrm{Hb}$ below $10 \mathrm{~g} / \mathrm{dl} \mathrm{ml}$ during the acute illness, whiel 5 hypernatraemic infants had $\mathrm{Hb}$ below $8 \mathrm{~g} / \mathrm{dl} \mathrm{ml}$. These 5 required blood transfusions during the acute illness. $\mathrm{Hb}$ often continued to fall during convalescence and 5 further hypernatraemic infants received blood transfusions for severe anaemia at this stage. The degree of anaemia was more closely related to the level of plasma sodium than to the plasma osmolality. Thus the infant in the 
series with the highest plasma sodium, $220 \mathrm{mEq} / \mathrm{l}$, with a plasma osmolality of $480 \mathrm{mOsm} / \mathrm{kg}$, had $\mathrm{Hb}$ on admission of $5.5 \mathrm{~g} / \mathrm{dl} \mathrm{ml}$ and required two blood transfusions during the acute illness, while the infant with the highest plasma osmolality, $517 \mathrm{mOsm} / \mathrm{kg}$, and severe uraemia and hyperglycaemia, with a plasma sodium of only $180 \mathrm{mEq} / \mathrm{l}$, had a minimum $\mathrm{Hb}$ of $12.5 \mathrm{~g} / \mathrm{dl} \mathrm{ml}$ during the acute illness, though a transfusion was needed 19 days after admission. The anaemic infants were healthy before their illness and showed no evidence of iron deficiency. They did not differ as a group from the normonatraemic except that they were younger and more severely ill.

Hypoproteinaemia. Total plasma proteins fell below $5 \mathrm{~g} / 100 \mathrm{ml}$ during treatment in 7 of 25 hypernatraemic infants where they were measured serially, but in none of 15 normonatraemic infants. In 5 of these 7 plasma had already been given in initial resuscitation because of circulatory failure. Severe hypoproteinaemia was seen in the very ill, and repeated plasma transfusions were needed to maintain a peripheral circulation in one infant.

\section{Discussion}

This study has shown that infants with severe hypernatraemic dehydration can be safely rehydrated within 48 hours using $0.18 \%$ saline in $4.3 \%$ dextrose, with the early addition of potassium, at a rate of $100 \mathrm{ml} / \mathrm{kg}$ estimated rehydrated weight per 24 hours. A fluid intake of $100 \mathrm{ml} / \mathrm{kg}$ per 24 hours when given to an infant receiving enough calories to reduce tissue breakdown to a minimum, receiving no solute excess requiring excretion, and with minimal insensible fluid losses, will theoretically provide 50-60 ml/kg per 24 hours for rehydration (Talbot, Richie, and Crawford, 1959). This fits well with the average weight increase of $6 \%$ during the first 24 hours found in those treated with the $\frac{1}{5} \mathrm{~N}$ saline regimen. Using this treatment, plasma osmolality should fall at around $2 \mathrm{mOsm} /$ hour, and the weight gain should be about $6 \%$ in the first 24 hours. This treatment regimen has since been used for all hypernatraemic infants until electrolytes are nearing normal, when the intravenous or oral intake is increased to $150 \mathrm{ml} / \mathrm{kg}$ per 24 hours, and the results have been satisfactory. Of the next 12 admissions with plasma osmolality greater than $350 \mathrm{mOsm} / \mathrm{kg}, 10 \mathrm{had}$ an uneventful recovery, 1 with cerebral haemorrhage was very ill and convulsed for the first 24 hours but made a good recovery, and 1 who was given $125 \mathrm{ml} / \mathrm{kg}$ per 24 hours in error had a single short episode of convulsions.
Infants treated with a faster rate of $0.45 \%$ saline were also rehydrated within $\mathbf{4 8}$ hours, but convulsed frequently and also became oedematous, suggesting that too much sodium was received during treatment. The omission of potassium early in therapy may have increased the incidence of oedema in these babies. $\frac{1}{2}$ saline given at the slow rate produced a poor fall in plasma osmolality and much slower rehydration; too slow, we feel for safety.

With greater appreciation of the importance of slow reduction of hyperosmolarity both mortality and the incidence of convulsions during treatment are decreasing. Convulsions are probably avoidable where irreversible brain damage has not occurred. In most reported series infants with sodium overload are also included, and as this condition has a different mortality and incidence of convulsions comparisons are difficult. Fairly representative were the findings of Morris-Jones, Houston, and Evans (1967) who reported 50 patients treated more than 10 years ago: $36 \%$ convulsed and $20 \%$ died, $16 \%$ probably as the result of hypernatraemia. More recently Bruck, Abal, and Aceto (1968) treated 59 hypernatraemic infants with no deaths. Of 30 treated with a polyionic solution at about $200 \mathrm{ml} / \mathrm{kg}$ per 24 hours none convulsed, while of 29 treated with $10 \%$ dextrose 7 convulsed. Our series of selected severely hyperosmolar infants, where the mortality was $13 \%$ and the incidence of convulsions $32 \%$ ( $21 \%$ probably unavoidable), can be compared with those infants of Morris-Jones et al. (1967) with a plasma sodium greater than $157 \mathrm{mEq} / \mathrm{l}$, where $71 \%$ convulsed. Animal experiments have shown that the rate of rehydration can affect the incidence of convulsions in hypernatraemia (Hogan et al., 1963), and that both sodium and potassium are needed in the rehydrating fluid for the best reduction in mortality and the fastest return of the body composition to normal (de Leon and Bergstrom, 1964).

It has been suggested that convulsions during treatment are of good prognosis and of little importance. This may be so in some cases. However, 2 of our infants with convulsions due to treatment were severely ill. One in status epilepticus required paralysis with curare and artificial ventilation for 16 hours. The other, whose convulsions were reasonably controlled and who was doing well, had a cardiac arrest 58 hours after the start of treatment, probably after a further convulsion. Fortunately, he made a full recovery after resuscitation. We feel these convulsions are potentially life-threatening and should be avoided.

It is generally thought that convulsions occurring during treatment are associated with cerebral oede- 
ma (Skinner and Moll, 1956; Weil and Wallace, 1956) and experimental work in animals supports this (Hogan et al., 1969). As hypernatraemia increases, breakdown of protein molecules in brain cells is thought to occur, producing more numerous osmotically active particles, so reducing brain cell shrinkage to some extent (McDowell, Wolf, and Steer, 1955; Logothetis, 1966). During rehydration with rapid falls of extracellular osmolality, the increased intracellular osmoles could lead to excess water passing into brain cells. Gradual reduction of plasma osmolality would give time for repair of the intracellular structure, and therefore a slow fall of plasma concentration, especially of sodium, is the aim of treatment. The situation in the brain is probably far more complex than this simple theory suggests, brain extracellular fluid being in equilibrium with both plasma and CSF, and glial cells protecting neurones by acting as osmotic buffers. The findings in this study that a single rate of fall of plasma osmolality could not be recommended as safe with all forms of treatment, that similar rates of fall were satisfactory with $\frac{1}{5} \mathrm{~N}$ saline but produced convulsions with $\frac{1}{2} \mathrm{~N}$ saline, and that the plasma sodium actually fell more rapidly in the $\frac{1}{5} \mathrm{~N}$ group with no ill effects, comes as a surprise and suggests that both rate of fluid received and its sodium content are important in the aetiology of convulsions during treatment. It is possible that overexpansion of the extracellular fluid of the brain with high sodium intakes may contribute.

Our experience has shown the importance of preventing excess fluid losses from skin and lungs during the carefully controlled rehydration which is the aim of therapy. A slow rate of rehydration will be harmful where there is a poor peripheral circulation, and an initial plasma expander must then be used to restore the circulation and renal function. Most plasma expanders contain a high concentration of sodium. In the small amount used, and where the basic rehydrating fluid is low in sodium this is unimportant. We have no experience of the use of sodium-free dextran in this situation. The use of sodium bicarbonate to correct acidosis will add a further sodium load, and needs careful consideration. Mild metabolic acidosis is not dangerous, and is corrected as well over 24 hours by rehydration alone as by the addition of alkali to treatment (Heese et al., 1966; Bruck et al., 1968).

Hypocalcaemia was not found to be important in hypernatraemia except where potassium was not added early in treatment. Hyperglycaemia, though common, was usually corrected rapidly, and there seems to be little indication for the routine use of insulin. It is probably due to the effect of hyperosmolarity on peripheral cells, impairing their ability to metabolize glucose (Stevenson and Bowyer, 1970). The one infant whose blood glucose rose further after the start of peritoneal dialysis with a solution of $1.36 \%$ glucose content, was still severely hyperosmolar at the time, and may have absorbed glucose from the dialysis fluid while still unable to metabolize it. Glucose can be absorbed from the peritoneum even with dialysis fluid of low glucose content (Boyer, Gill, and Epstein, 1967).

This study has shown two other complications which occur in those severely affected, anaemia and hypoproteinaemia, and we feel it is important to recognize and correct these conditions. Adequate haemoglobin and albumin levels are needed to maintain the colloid osmotic pressure of the blood, and thus a satisfactory circulation. This is particularly important in the severely ill, where any further impairment of renal function or of brain perfusion and oxygenation can have disastrous effects. The rapid fall of haemoglobin in previously healthy infants and the continuing fall seen during convalescence suggest a haemolytic cause, and this is supported by the findings of Kim, Borges, and Holliday (1962) in humans and rats, that hyperosmolarity increases red cell fragility. They found that hyperosmolarity due to raised sodium concentrations had a greater effect than that due to glucose or urea. Falls of plasma proteins are probably the result of shock, through anoxic damage to capillaries and leakage of protein from the circulation into the interstitial fluid.

We are grateful to Professor L. B. Strang for his interest, to all the paediatricians at Alder Hey Children's Hospital and the Royal Liverpool Children's Hospital for permission to study their patients, especially to Drs. E. Hall, R. Hendrickse, and R. S. Jones; to Mr. Tweedie for statistical advice; to Mr. F. Mead for use of the computer of the Institute of Child Health; to Mr. B. Jones for developmental testing; to Mrs I. Walker for help with follow-up attendances; to Sister M. Garawal and all members of the nursing staff concerned with the care of these babies and the collection of samples.

A.B. was in receipt of a grant from the Cancer and Polio Research Fund.

\section{REFERENCES}

Ahmed, I., and Agusto-Odutola, T. B. (1970). Hypernatraemia in diarrhoeal infants in Lagos. Archives of Disease in Childhood, 45, 97.

Boyer, J., Gill, G. N., and Epstein, F. H. (1967). Hyperglycemia and hyperosmolality complicating peritoneal dialysis. Annals of Internal Medicine, 67, 568.

Bruck, E., Abal, G., and Aceto, T. (1968). Therapy of infants with hypertonic dehydration due to diarrhea. American fournal of Diseases of Children, 115, 281. 
Heese, H. de V., Tonin, C., Bowie, M. D., and Evans, A. (1966). Management of metabolic acidosis in acute gastroenteritis. British Medical fournal, 2, 144.

Hogan, G. R., Devivo, D., Gill, S. R., Master, S., Sotos, J., and Dodge, P. R. (1963). Development of seizures during rehydration of hypertonic rabbits. Fournal of Pediatrics, 63, 729.

Hogan, G. R., Dodge, P. R., Gill, S. R., Master, S., and Sotos, J. F. (1969). Pathogenesis of seizures occurring during restoration of plasma tonicity to normal in animals previously chronically hypernatremic. Pediatrics, 43, 54.

Kim, J., Borges, W. H., and Holliday, M. A. (1962). Correlation between rbc osmotic fragility and serum sodium. American fournal of Diseases of Children, 104, 281.

de Leon, A. S., and Bergstrom, W. H. (1964). Hypertonic dehydration. New York State fournal of Medicine, 64, 2157.

Logothetis, J. (1966). Neurologic effects of water and sodium disturbances. I. General mechanism, hypernatremic syndromes. Postgraduate Medicine, 40, 408.

McDowell, M. E., Wolf, A. V., and Steer, A. (1955). Osmotic volumes of distribution. American fournal of Physiology, 180, 545 .
Morris-Jones, P. H., Houston, I. B., and Evans, R. C. (1967). Prognosis of the neurological complications of acute hypernatraemia. Lancet, 2, 1385.

Skinner, A. L., and Moll, F. C. (1956). Hypernatremia accompanying infant diarrhea. American fournal of Diseases of Children, 92, 562.

Stevenson, R. E., and Bowyer, F. P. (1970). Hyperglycemia with hyperosmolal dehydration in nondiabetic infants. fournal of Pediatrics, 77, 818.

Stickler, G. B. (1967). Warning regarding administration of fluids. Clinical Pediatrics, 6, 323.

Talbot, N. B., Richie, R. H., and Crawford, J. D. (1959). Metabolic Homeostasis. Harvard University Press, Cambridge, Mass.

Weil, W. B., and Wallace, W. M. (1956). Hypertonic dehydration in infancy. Pediatrics, 17, 171.

Correspondence to Dr. A. Banister, Basildon Hospital, Nethermayne, Basildon, Essex SS16 5NL. 